\title{
Higher education in Russia: problems of environmental personnel training
}

\author{
Chingiz Yakubov ${ }^{1}$ and Anzhelika Luchinkina ${ }^{1, *}$ \\ ${ }^{1}$ Crimean Engineering and Pedagogical University named after Fevzi Yakubov, Uchebnyy Ln., 8, \\ 295015 Simferopol, Republic of Crimea, Russia
}

\begin{abstract}
In the course of the study, it was revealed that the criteria for the effectiveness of training engineers is the compliance of their competencies formed in the process of training with the requirements of the production in General and the employer in particular. Aims of the present study: to identify the main global trends in engineering education, determine the criteria for the effectiveness of training engineering personnel and analyze the compliance of graduate training with these requirements. Methodology, methods. The study was conducted among graduates; teachers of engineering areas of training of the Crimean engineering and pedagogical University named after Fevzi Yakubov, as well as among managers of enterprises of the Republic of Crimea, potentially being employers for the studied specialties during 2019 A total of 412 respondents were interviewed. Of these, there are 248 graduates of engineering training areas (final courses), 92 teachers of engineering training areas, and 72 employers. The experimental object of the study was engineering education in higher education. Results: Engineering education is a continuous process of accumulating General cultural and professional competencies in the direction of secondary education - secondary vocational education - technical University. The criterion for the effectiveness of training engineers is the compliance of their competencies formed in the process of training with the requirements of the production in General and the employer in particular.
\end{abstract}

\section{Introduction}

The modern stage of scientific and technological progress is characterised by the increasing role of transborder technologies, cloud computing and storage, neural networks and other cyber physical systems, contributing to the digitalisation of all personal life spheres. Rapidly increasing information scopes and the need for their timely processing brings the interaction of man and the cyber physical system to the fore in both production and consumption. Today, programmers, IT specialists, and engineers are among the most popular professions in Russia and the world. At the same time, it should be appreciated that the use of digital platforms, the increasing role of artificial intelligence and the emergence of robotics workshops require a qualitatively different training of engineering staff than 5-10 years ago.

\footnotetext{
${ }^{*}$ Corresponding author: aluch@ya.ru
} 
The expansion in the number of universities providing training in engineering specialties does not remove the issue of the quality and topicality of engineering training, taking into account not only the current zone, but also the zone of the nearest development of technical progress.

Technical universities were faced with an existential contradiction: the country needs competent engineers, who are able to work with new intelligent systems and have a high ability to learn, but the widespread fascination with humanities education, problems in the system of secondary basic and general education, and the desire to earn easy money has led to a decrease in the attractiveness of engineering professions for enrollees. This dissonance between demand and need leads to the fact that students, who do not have a high level of achievement in mathematics, physics, chemistry, computer science and do not have the necessary potentials for the development of engineering competencies, enter the technical areas of training. At the same time, there is an understanding that the main competitive advantage of any country is in the development of its human resources.

Despite the urgency of the problem, scientific activities in this area are not enough, and the definition of methodological grounds for building a system of psychological and pedagogical support for engineering education could bring measurable theoretical and practical results. Questions of pre-university support of engineering education require answers: how to make a selection in engineering classes? What are the requirements for teachers? What is the final result of school engineering education? It remains a problematic issue in today's transitive society to determine the set of professional competencies of an engineer at all stages of his training. The question of students' choice of engineering areas of training in the specialty is undoubtedly of practical importance.

\section{Aims. Research hypothesis}

Aims of the present study: to identify the main global trends in engineering education, determine the criteria for the effective-ness of training engineering personnel and analyze the compliance of graduate training with these requirements.

Research hypothesis: the level of psychological safety of the educational environment is determined by the chosen education system.

\section{Literature review}

Analysis of scientific literature on the problem of engineering training in Russia has allowed us to identify certain educational traditions:

Firstly, it is the fundamental nature of education. This tradition dates back to the signing of the Decree by Peter 1 "On the organisation of School of mathematical and navigation sciences in Moscow" and is based on the teaching of exact sciences to engineering students [1].

Secondly, it is the elitism of engineering education. Engineering education in Russia required preliminary training in a number of disciplines (physics, chemistry, mathematics) and therefore could be available to few [2].

Thirdly, engineering education in Russia is determined by the direction from the general to the special: from general theoretical disciplines to special ones, from theory to practice $[2$, $3]$.

Fourthly, it is the "Education - Science - Industry" triad. The main components of engineering education in Russia become the study of fundamental exact sciences (physics, chemistry, and mathematics), practical training and communication with industrial production. 
The unity of deep theoretical knowledge and practice throughout the entire training period formed the basis of the "Russian method" in the training of engineers $[4,5]$.

Fifthly, it is requirements for the qualification of teachers and training of students. If the requirements for the qualification of teachers can be attributed to the beginning of engineering training, the criteria for selecting prepared applicants came to Russia from France, where entrance exams in physics, chemistry, and mathematics were first introduced for applicants to the Polytechnic school. This approach to selection has shown its effectiveness and has got used to Russian engineering education [1, 6-11]. In addition, in the middle of the XIX century in Russia, the first specialised classes were created (in-depth study of exact sciences), and the first documents of the Soviet government assigned free and compulsory, general and polytechnic education for all children of both sexes under 17 years of age; 3) wide development of vocational education for persons from the age of seven years in connection with General polytechnic knowledge [1]. This approach brought awareness of the choice of profession on the part of schoolchildren and their higher level of training in the disciplines of the scientific cycle and exact sciences $[1,2]$.

The analysis of scientific literature makes it possible to state that engineering training in Russia before the 60s of the XIX century was one of the best in the world, which provided the country with a breakthrough in the main technical areas $[3,9,12]$. Scientists note that it was at this time that the model of training engineers developed, which was based on these traditions and provided high quality training for engineers. The prestige of the profession, in turn, was conditioned by rapid scientific and technical progress, the attitude to engineering of society, and high wages [13-15].

At the same time, in modern research in the field of engineering staff training, it is noted that despite the current demand for the profession, there is a shortage of motivated applicants for engineering training $[12,16]$, which is expressed in the discrepancy between the number of incoming students and the number of young professionals working in the specialty [17, $18]$.

Scientists gear the decline in the prestige of engineering education to the general crisis of the education system and the global economic crisis: the humanitarisation of education [3, 4], the intellectual investment of training specialists [19, 20], the problem of the material and technical base for their training (rapid obsolescence of equipment) [21].

Analysis of Federal State Educational Standards of the Third Generation in the field of engineering training has shown the need for graduates to form not only professional, but also common cultural competencies that allow students to interact constructively with society [22]. It should be noted that the training of highly specialised engineers is still giving way to universality [23].

It is interesting to analyse the requirements of the International engineering Alliance and the European Federation of national engineering associations for the qualification of an engineer. In addition to general professional competencies related to the level of knowledge in the chosen field, the ability to use and create software for engineering activities, attention is focused on the ability to analyze engineering problems, develop and make engineering decisions, and be able to evaluate engineering activities. It should be noted that the level of social responsibility, legal literacy, and managerial competence is of great importance in the qualification requirements for an engineer. At the same time, the European Federation of national federations of engineers, assessing the competence of engineers, notes more general competencies based on general knowledge of the principles of engineering, the ability to use technical information, the ability to innovate and design activities, and interdisciplinarity. Among the necessary competencies is the ability to build industrial relations based on existing technical, financial and human conditions [24].

We would like to note that this set of competencies is not final, but requires the presence of basic competencies for the applicant who has chosen the engineering direction of training 
[24]. Such a base may well be formed by training in a specialised class. Scientists distinguish several following blocks of the competency model of a graduate of a profile class: training, profile orientation, moral education, social and personal maturity. It is on the basis of the initial competencies that the professional competence of a future engineer can be successfully developed. Thus, the block of profile orientation includes a value orientation on the choice of profession, which can later become the basis for the formation of a stable professional motivation. Creating a school-university system can not only ensure the continuity of engineering education, but also guarantee a high quality of knowledge, orientation to practice and informed choice of profession [25, 27]. Today, the essence of specialised classes is in early career guidance of students and preparing them for further technical education. Renewed interest in engineering is associated not only with the growth of scientific and technological progress, but also with the understanding that the country's competitive ability depends not a little on the development of its technical sphere [28].

In the wings of the shortage of engineering staff, the issue of selecting students for engineering majors is no less important [6]. Turning to the traditions of engineering education in Russia, we would like to note the decline in the level of training of applicants in physics, mathematics, and chemistry, which makes it difficult to master general theoretical courses in exact Sciences. Part of the solution to this problem is to increase the number of engineering classes in Russian schools, and to focus these classes on interaction with General education organizations, enterprises, research institutes, laboratories and centers. According to teachers, research scientists, training in specialised engineering classes should contribute to the formation of systematic thinking of students [27].

Nevertheless, an analysis of publications on the problem of training students in specialised engineering classes has shown that about $30 \%$ of graduates do not choose engineering areas of training, when entering higher education institutions, and of those who have received at least $15 \%$ drop out during training and $15 \%$ do not work later in their specialty. These facts indicate the need for psychological and pedagogical support throughout engineering education.

No less important is the problem of personal characteristics of graduates. In psychology, it is an established fact that labour productivity decreases as a result of conflict relationships, depression, low self-esteem and lack of motivation to work.

The analysis of scientific literature on the research problem allowed us to make a rating of the most common General characteristics of an engineer's professional activity. It should be noted that the rating is headed by personal characteristics - creativity, motivation of professional activity, organisational and leadership abilities, communication potential, tolerance, systematic thinking, ability to work in a team, responsibility and performance discipline, the ability to self-development. The second place is taken by the block of general theoretical training-knowledge of foreign languages, knowledge in the field of psychology, management and financial activities [24].

The introduction of personal components in the content of engineering education fully meets modern requirements for training specialists, but the above characteristics for development at the university stage should be laid at the school stage.

This approach also requires psychological and pedagogical support of students at all stages of engineering education. In this direction, there are also a number of studies: psychological and pedagogical support of engineering education of students with hearing impairment was studied by A. G. Stanevsky, L. P. Khrapylina [29]; the preparation of future engineers for research activities is analysed in the works of O. O. Gorshkova [30]; experimental methods of studying theory in engineering universities are proposed in the articles of $\mathrm{V}$. N. Kruglikov; the system of pre-University training is described in the article by I. V. Tsvetkov, D. Yu. Pravnik [31]. In the research of other scientists, attention was focused on the components of the model of continuous education of the school of the future (on the example of an 
engineering school) [29-32]. In most cases, pedagogical support is limited to organising specialised classes, olympiads and engineering project competitions. However, the psychological component of engineering training remains outside the scope of consideration, which reduces the absolute value of the proposed models of engineering education. In addition, these studies do not offer methods of systematic work with students to form their stable motivation to choose an engineering direction of training and further work in this specialty, as well as the development of basic competencies.

This way, the current system of secondary and higher education implies a conscious choice of training direction by graduates of specialized classes and specialised schools, high motivation for further training and compliance with the professional requirements of graduates, as well as the presence of a certain set of personal characteristics. However there is a certain imbalance between the requirements for professional competence and the actual level of psychological readiness of an engineering graduate.

\section{Materials and methods}

The experimental object of research became engineering education in higher education. The study was conducted among graduates, teachers of engineering training areas of the Crimean Engineering and Pedagogical University named after Fevzi Yakubov, as well as among the heads of enterprises of the Republic of Crimea, who are potentially employers for the studied specialties. A total of 412 respondents were polled. The respondent group involves 248 graduates of engineering training courses (final courses), 92 teachers of engineering training courses, and 72 employers.

During the research the following empirical and experimental tasks were solved:

Compare the existing criteria for the effectiveness of graduate training with the existing social attitudes of employers.

Analyse the success of training and the stability of professional motivation of engineering graduates.

Develop a model of psychological and pedagogical support of engineering education at the pre -University and higher education stages.

The methodological basis of the study became:

A systematic approach to engineering education allows us to study not only the process of engineering education of a person, but also its features at each stage of training (school and university), including psychological (motivation, leading values, personal characteristics) and pedagogical (content and forms of education) components;

A professional approach that allows to create professionally significant qualities, criteria for readiness for professional activity.

The study used the method of theoretical analysis of the works of the Russian and foreign scientists on the problem of engineering training in higher education institutions, a survey of employers to determine the necessary professional competencies of future engineers and the level of satisfaction with the training of young professionals; a survey of teachers to identify problem areas in the training of engineering personnel; a survey of students to identify the main motives and the level of satisfaction with training; control sections of knowledge to determine the current level of knowledge of students.

The study was conducted throughout 2019 and included two stages. At the first stage, a theoretical analysis of the scientific literature on this problem was carried out and the main performance indicators of engineering graduates were identified. At the second stage, was studied the compliance of the selected indicators with the actual ones formed by graduates of engineering areas of training from the position of the employer. In addition, were studied investigated the reasons for low professional motivation of graduates and proposed a model of psychological and pedagogical support for engineering education at all levels. 


\section{The results of research and discussion}

The results of the study allowed us to present the following questions for discussion:

\subsection{Difficulties of employers in determining the necessary set of professional and universal competencies of an engineer}

The results of a survey of employers to identify the compliance of the necessary and available professional, general cultural and personal competencies of graduates of the bachelor of engineering courses are shown in Figure 1.

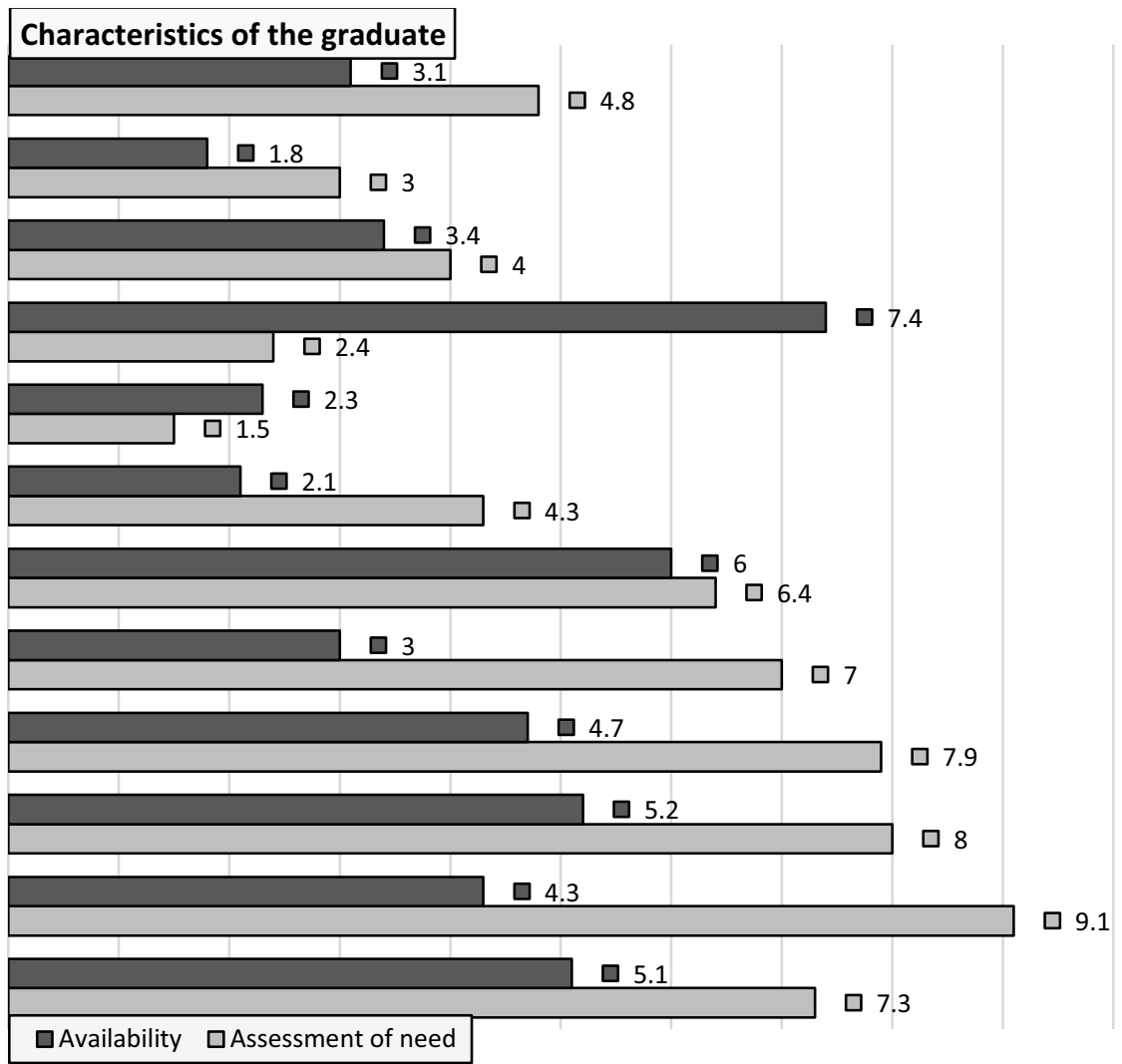

$\mathbf{1}$ - knowledge of the principles of engineering; $\mathbf{2}$ - ability to create software for engineering activities; 3 ability to analyse engineering problems; $\mathbf{4}$ - ability to develop and make engineering decisions; $\mathbf{5}$ - ability to evaluate engineering activities; $\mathbf{6}$ - social responsibility; 7 - legal literacy; 8 - managerial competency; 9 ability to use technical information; 10 - ability to innovate and design; $\mathbf{1 1}$ - interdisciplinarity; $\mathbf{1 2}$ - ability to build industrial relations.

Fig. 1. Correlation of the levels of necessary and real competencies of graduates from the point of view of employers

As can be seen in figure 1, there are significant differences (at $\rho=0.05$ ) between the necessary and available level of development of the following competencies: knowledge of the principles of engineering, the ability to create software for engineering, the ability to analyze engineering problems, the ability to develop and make engineering decisions, the ability to evaluate engineering activities, legal literacy, the ability to use technical information, the 
ability to innovate and design activities, interdisciplinarity, the ability to build industrial relations. All results are calculated on the basis of average scores on a ten-point scale.

According to employers, one of the most important abilities of a young engineer is multitasking (the ability to quickly make a decision when setting several tasks at the same time). As an example, employers often cite the distribution of engineer's attention when controlling the operation of numerical control machines, when one engineer has to hold several machines and programmes in attention at the same time.

At the same time, employers distinguish legal literacy and managerial skills as insignificant for an engineer.

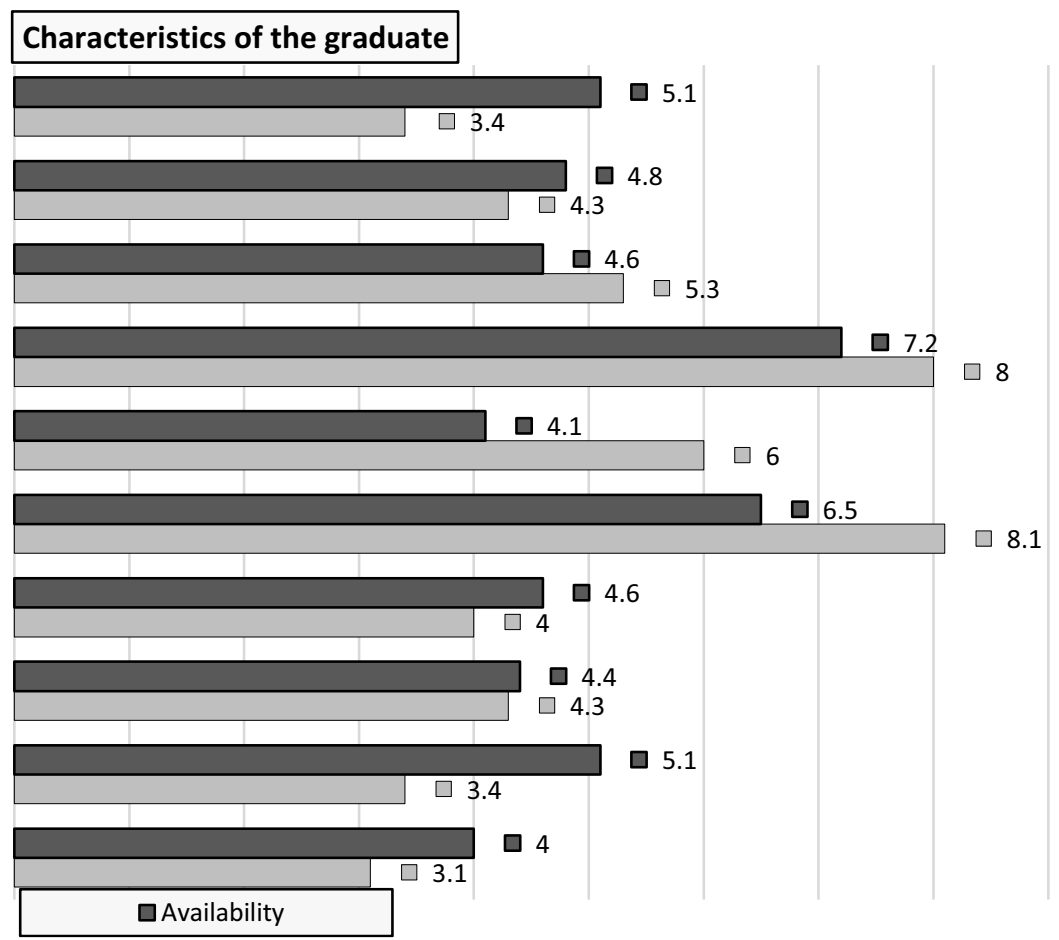

$\mathbf{1}$ - creativity; $\mathbf{2}$ - organisational and leadership abilities; $\mathbf{3}$ - communication potential; $\mathbf{4}$ - tolerance; 5 systematic thinking; $\mathbf{6}$ - ability to work in a team; $\mathbf{7}$ - responsibility and performance discipline; $\mathbf{8}$ - ability to self-development; 9 - foreign language proficiency; 10 - knowledge in the field of psychology, management, financial activities.

Fig. 2. Correlation of levels of necessary and real characteristics of graduates from the point of view of employers

When discussing the identity of a young specialist who is hired, the company's managers pay special attention to his or her ability to work with technical documentation, which they considered not the most important before hiring an employee. The analysis of the need for individual personal skills and their availability for graduates according to employers is shown in figure 2.

As can be seen in figure 2, employers do not consider these characteristics professionally important, noting their severity at the bottom of the 10-point scale. Significant differences are noted when evaluating such characteristics as creativity, organisational and leadership abilities, systematic thinking, ability to work in a team, knowledge in the field of psychology, management, and financial activities (at $\rho=0.05$ ). 
In addition, the survey revealed that among the necessary individual characteristics of a graduate, employers note the role of motivation of a young specialist to work in the profession.

\subsection{The need to consider engineering education in the direction of additional education of children-specialised classes - engineering classes - engineering areas of training in educational organisations of higher education}

The conducted survey of teachers working in engineering specialties revealed problem areas in the training and current level of knowledge of future engineers. So, more than $30 \%$ of teachers point to insufficient school preparation of applicants, lack of knowledge in the field of drawing. A retrospective analysis of the control cross-sections of knowledge confirmed the existence of problems at the school curriculum level.

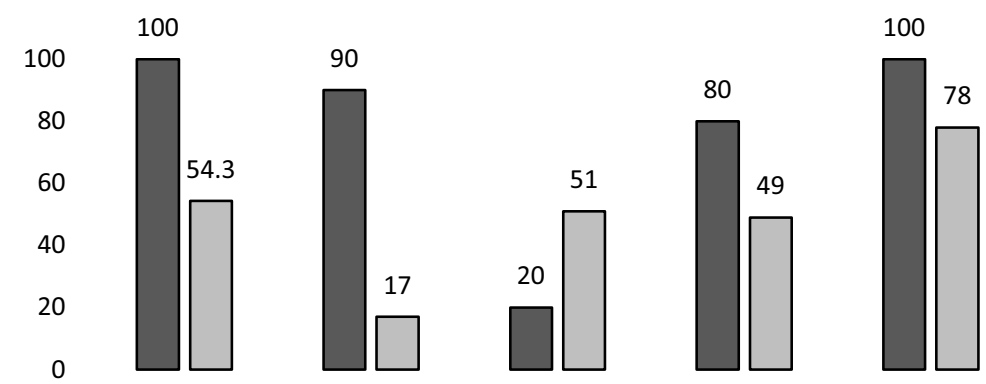

$\square$ Students with specialized training in exact subjects (in-depth study, olympiads)

a Students who do not have specialized training at school

$\mathbf{1}$ - quality of knowledge; $\mathbf{2}$ - scientific activity; $\mathbf{3}$ - external motives for choosing a profession;

4 - internal motives for choosing a profession; 5 - satisfaction with learning.

Fig. 3. Survey results of students of engineering training areas.

The research revealed that only $7 \%$ of graduates ( 21 people), who took part in the study, had previously studied in specialised classes with advanced study of physics and mathematics (Figure 3). Of the study population, 4 students participated in subject olympiads, 2 respondents were previously engaged in the Minor Academy of Sciences. This group of respondents had a stable high academic success rate (more than 3 consecutive semesters) and a high level of research activity. The level of satisfaction with training for this group was also high.

As can be seen in Figure 3, graduates who previously had specialised training in schools, winners or participants of subject olympiads in the subjects of the physics and mathematics cycle, have higher indicators of the quality of knowledge and scientific activity, which in principle confirms the data of earlier studies.

A group of graduates who did not previously have specialised training in schools show lower results in terms of the quality of knowledge and scientific activity. The results obtained confirm the need for a closed school-university-production system.

5.3. The presence of a large number of graduates with external motivation and lack of motivation for employment in general requires psychological analysis and building a system of correctional work with students throughout the entire period of training 
As shown by the research, a group of respondents, who previously had a specialised education, notes interest and desire to create a new profession as the main motives for choosing a profession (80\%). At the end of training, $100 \%$ of graduates were employed in their specialty. At the same time, a group of graduates, who did not previously have specialised training in schools, in most cases, demonstrates external motivation (or lack of motivation at all) to choose a profession: friends advised, parents arranged, there is nowhere else to go. The graduates of this group also refer to the lack of school knowledge as the main problems in learning. Employment in this group of graduates is $67 \%$. More than $30 \%$ of graduates are invited to work after completing their internship.

Thus, the study confirmed the need for psychological and pedagogical support of engineering education.

We propose a psychological and pedagogical model of supporting the individual in the process of engineering education.

The model is based on the principles of continuity of engineering education. In this regard, it includes a stage of pre-University training, namely specialised classes (classes with in-depth study of physics, mathematics, chemistry; engineering classes), additional education for children (quantoriums, engineering and technical circles and sections, Small Academy of Sciences) and competitions. At the stage of higher education, the main principle becomes practice orientation within the triad of education-science-production.

The model contains four modules: educational-instrumental, motivational, personal-oriented and professional-oriented.

The educational and instrumental module includes training of teachers working in engineering classes and in engineering training areas in higher education organisations, as well as monitoring and correcting the content of engineering education and the quality of mastering theoretical knowledge and practical skills of students.

The motivational module is based on measures to form professional motivation for engineering activities at all stages of training. At the pre-university stage, this module may include performing practice-oriented tasks, creating engineering or technical projects aimed at solving specific problems of the economy and having a visible result. At the university stage, the formation of professional motivation is assumed directly in the workplace with psychological support in the awareness of the importance of the tasks. During the implementation of the module's activities, project activities are assumed.

The personality-oriented module includes the formation and further development of such basic characteristics as creativity; organisational and leadership abilities; communication potential; and the ability to self-development. At the pre-university and university stage, one of the main tasks is to develop the ability to make decisions in a multitasking environment. The main methods of work are modeling trainings.

The professionally-oriented module establishes the unity between education, science and production and contains activities aimed at the formation of professional competencies, including: knowledge of the principles of engineering; the ability to create software for engineering; the ability to analyse engineering problems; the ability to develop and make engineering decisions; the ability to evaluate engineering activities; the ability to use technical information; the ability to innovate and design; ability to build industrial relations.

The proposed model of psychological and pedagogical support of engineering education allows us to take into account its multi-stage, continuity and consistency. In order to test this model, an innovation platform has been created in the Republic of Crimea, where qualitative and quantitative indicators of engineering graduates' training will be measured and a comparative analysis will be made with the results of the control group. The expert group is the Council of employers of the Crimean Engineering and Pedagogical University named after Fevzi Yakubov, which includes Directors of large industrial enterprises of the Republic. 


\section{Discussion}

The scientific novelty of this model lies not only in the coverage of all stages of engineering training, but also in the consistency, in the integrity of the formation of engineering competencies. It should be noted that in earlier works in this area, both Russian [33] and foreign authors [34, 35], attention is focused on the educational and professional components, while the psychological component remains outside the scope of consideration.

At the stage of pre-university training, schools and the Crimean Engineering and Pedagogical University signed agreements on the network implementation of educational programs. The program of specialized engineering classes includes robotics, bioengineering, 3D design, and drawing. Moreover, the development of individual projects involves industrial practice, which gives schoolchildren the opportunity to get acquainted in practice with the specifics of engineering. It should be noted that the transfer of the educational activities of high school students to the university base allows students to adapt to the university environment. The educational and instrumental module at this stage is implemented by creating educational programs for the basic part of the curriculum and optional courses by university teachers. The experts of such programs are schoolteachers and engineers with at least 5 years of experience.

In contrast to the previously existing model of specialized classes [36], this system is designed for a continuous relationship between school, university and industry, which makes it more efficient.

At the university stage, the instrumental-educational level has its own specifics, which consists in the formation of a practice-oriented curriculum and the introduction of electives in the first years in such basic subjects as physics, higher mathematics, and drawing.

The motivational module at both stages is implemented in the process of teaching curriculum disciplines and includes project activities. Thus, students in the robotics course analyze the need to design certain types of robots and receive orders for their assembly from university staff. In one of the cases, schoolchildren assembled a robot that distributes advertising materials of the University to applicants. Most often, the formation of a sustainable research interest becomes the basis of professional motivation at this stage. Note that the joint project activities of schoolchildren and students are a strong motivation.

The personality-oriented module is implemented through psychological disciplines: engineering psychology, labor psychology, psychology of professional self-determination. Pilot tests have shown that the ability for self-development, the ability to solve professional problems in multitasking conditions is higher for those students who are included in this experiment and have received appropriate training.

The professionally-oriented module is implemented directly in production and involves the integration of production and the university not only during practical training, but also by creating production laboratories at the university. This approach makes the engineering learning environment realistic.

\section{Conclusion}

1. Engineering education is a continuous process of accumulation of general cultural and professional competencies in the direction of secondary education - secondary vocational education - technical university. At the level of school education in the world practice, there is a differentiation in abilities and aptitudes, which implies the choice of a training profile and the formation of general cultural and professional competencies. At the level of secondary vocational education, working competencies are formed that allow the student to find 
employment in a particular technical specialty. University education forms all types of competencies (general cultural, general professional, professional), which allows you to get the profession of engineer.

2. The criteria for the effectiveness of training engineers are the compliance of their competencies formed in the course of training with the requirements of production in general and the employer in particular. Employers call multitasking one of the most important necessary competencies in the conditions of digitalisation of production.

3. The results of the research showed discrepancies in the assessment of the necessary and available competencies and characteristics of young professionals by employers. Personal characteristics of an employee are not always taken into account, and General cultural competencies are not sufficiently evaluated in the professional block.

4. The model of psychological and pedagogical support is based on the principles of systematic and continuous engineering education and contains educational and instrumental, motivational, personal-oriented and professionally-oriented modules. The implementation of this model will improve the quality of engineering education and will contribute to a conscious choice of engineering specialty.

\section{References}

1. A. I. Rudskoy, A. A. Aleksandrov, P. S. Chubik, A. I. Borovkov, P. I. Romanov, A. N. Sharapov, Strategy for the development of engineering education in the Russian Federation for the period until 2020. Project, 55 (St. Petersburg: Publishing House of the Polytechnic University, 2017)

2. D. L. Saprykin, Engineering education in Russia: history, concept, prospects. Higher education in Russia, 1, 125-137 (2012)

3. V. A. Akatiev, L. V. Volkova, Engineering education in post-industrial Russia. Modern problems of science and education, 5, 40 (2014)

4. H. A. Thagapsoev, M. M. Yakhutlov, To problems of engineering education in modern Russia. Quality. Innovation Education, 8-10(135-137), 11-17 (2016)

5. N. P. Kirillov, The methodology of the concept of engineering education in modern Russia (philosophical, scientific and pedagogical aspect). Engineering Education, 11, 10-17 (2012)

6. J. Preece, The Trouble with Higher Education: A critical examination of our universities. International Journal of Lifelong Education, 29(6), 770-772 (2010)

7. M. N. Garanina, V. V. Kondratiev, Methodology of innovative engineering education. Kazan Science, 5, 11-19 (2012)

8. E. F. Zeer, V. S. Tretyakova, I. A. Kurochina, T. D. Bukovei, T. V. Beresneva, Teacher's Competitiveness at Different Stages of Professional Development. Humanities \& Social Sciences Reviews, 7(4), 1108-1119 (2019)

9. M. Waring, C. Evans, Understanding Pedagogy: Developing a critical approach to teaching and learning, 274 (London, Routledge, 2014)

10. S. Brophy, S. Klein, M. Portsmore, C. Rogers, Advancing Engineering Education in P12 Classrooms. Journal of Engineering Education, 97, 369-387 (2008)

11. G. N. Akhmetzyanova, Formation of the competency model of a graduate of a specialized engineering class, Prospects of science, 5(7), 51-53 (2010)

12. N. P. Kirillov, Yu. S. Plotnikov, An innovative model of engineering education: a triple helix metaphor. Management Problems in Social Systems, 4(6), 74-86 (2012) 
13. O. I. Rebrin, I. I. Sholina, New models of engineering education, University Management: Practice and Analysis, 2(102), 61-71 (2016)

14. G. Gibbs, S. Habeshaw, T. Habeshaw, 53 Interesting Things to do in Your Seminars and Tutorials, 134 (Virginia: Technical and Educational Services Ltd., 2012)

15. J. Gainsburg, The mathematical modeling of structural engineers. Mathematical Thinking and Learning, 8, 3-36 (2006)

16. D. Radcliffe, Engineering Competence An Interpretive Investigation of Engineering Students' Professional Formation. Journal of Engineering Education, 100, 703-740 (2011)

17. J. A. Stone, Integrating Apple iPads into University Computing Courses. International Journal of Modern Education and Computer Science (IJMECS), 8(9), 1-11 (2016)

18. G. N. Vovchenko, U. A. Albekov, F. T. Romanova, V. T. Epifanova, Study of Factor, Which Facilitate Increase of Effectiveness of University Education. International Journal of Educational Management, 31(1), 12-20 (2017)

19. M. I. Abashin, A. L. Galinovsky, A. R. Denisov, M. V. Zosimov, Promising models of engineering education. Bulletin of Kostroma State University. Series: Pedagogy. Psychology. Sociokinetics, 23(2), 6-11 (2017)

20. S. A. Bezklubaya, The humanitarian environment of a technical university as the basis for the formation of a competitive specialist. Human Capital, 5(113), 56-68 (2018)

21. V. A. Sultanova, S. O. Chechina, Human Capital as a Key Factor of Economic Growth in Crisis. European Research Studies Journal, 19(2), 72-79 (2016)

22. C. Shawn, I. Hewer, The impact of the Bologna process on nursing higher education in Europe: A review. International Journal of Nursing Studies, 51(1), 150-156 (2014)

23. R. A. W. Tortorella, C. N. S. Kinshuk, S. Graf, A Classification Framework for Contextaware Mobile Learning Systems. International Journal of Modern Education and Computer Science (IJMECS), 9(7), 1-11 (2017)

24. A. L. Galinovsky, Yu.V. Badanina, V.A. Moiseev, Competency portrait of a specialist in new models of engineering education. Bulletin of Perm National Research Polytechnic University. Problems of linguistics and pedagogy, 3, 139-149 (2017)

25. V. N. Khalamov, A model of additional education of children for the training of engineering personnel in Russia. Public Education. 2-3(1455), 135-138 (2016)

26. R. W. Lent, Social cognitive predictors of academic interests and goals in engineering: Utility for women and students at historically black universities. Journal of Counseling Psychology, 52(1), 84-92. (2005)

27. O. A. Karlova, N. I. Pak, The model of continuing education of the school of the future (for example, an engineering school). Open Education, 4(99), 98-104 (2013)

28. A. G. Stanevsky, L. P. Khrapilina, Conceptual approaches to designing key areas for the organization of training for people with hearing impairment in undergraduate programs in the field of education «Engineering, Technology and Engineering». Psychological Science and Education, 22(2), 87-96 (2017)

29. I. V. Tsvetkov, D. Yu. Pravnik, The system of pre-university training «school - NRNU MEPhI». Higher education in Russia, 6, 121-125 (2017)

30. O. O. Gorshkova, Concept of research training of technical universities students. The European Proceedings of Social \& Behavioural Sciences EpSBS364-372 (2019)

31. V. N. Kruglikov, Experimental methods of studying theory in an engineering university. Education and Science, 20(6), 50-69 (2018) 
32. S. Allie, M. N. Armien, N. Burgoyne, J. Case, et al., Learning as acquiring a discursive identity through participation in a community: Improving student learning in engineering education. European Journal of Engineering Education, 34(4), 359-367 (2009)

33. E. M. Dorozhkin, E. F. Zeer, Methodology of vocational pedagogical education: theory and practice (theoretical and methodological foundations of vocational pedagogical education). Education and Science, 9, 4-20 (2014)

34. G. Racko, E. Oborn, M. Barrett, Developing collaborative professionalism: an investigation of status differentiation in academic organizations in knowledge transfer partnerships. The In-ternational Journal of Human Resource Management, 30(3), 457478 (2019)

35. N. Salzman, D. Ricco George, M. Ohland, Pre-College Engineering Participation Among First-Year Engineering Students. School of Engineering Education Graduate Student Series, 6, 1-29 (2014)

36. E. G. Creamer, Yu. Rongrong, Involvement in Out-of-Class Activi-ties: A Mixed Research Synthesis Examining Outcomes with a Focus on Engineering Students. Journal of STEM Education: Innovations \& Research, 18(2), 10-16 (2017) 